\section{Care home placement and human rights}

In their editorial examining the pros and cons of different places of living for older people, Bally and Jung considered who enters residential and nursing (care) homes and how care in these settings might be improved. ${ }^{1}$ Research cited drew attention to factors that have a bearing on quality of life and respecting people's wishes. ${ }^{2}$ GPs should be able to identify those who may benefit from a care home, ${ }^{3}$ but should consider the person's cognitive abilities, perceptions, and preferences. ${ }^{4}$ They noted the importance of advance care planning, integrated care models, and individualised care.

We feel that some of these matters should also be considered from a legal and human rights perspective, as care home placements will often have a profound and enduring impact on older people's liberty, security, and family life - which are fundamental human rights. In England and Wales, the Mental Capacity Act 2005 (MCA) is an essential safeguard in this respect and its provisions are often at the forefront of GPs' minds when residence capacity assessments and best-interests decisions are being made. Yet widespread evidence suggests that the MCA's principles are still not 'embedded' as well as they should be in clinical practice. ${ }^{5}$ This is concerning, particularly when a move into care is being considered, given the impact that this will have on an older person's dignity and human rights. A recent study of patients with dementia discharged from general hospital found that ill-conceived capacity assessments and 'best interests' decisions that failed to adhere to the legal (and ethical) standards of the MCA could result in institutional placements being the 'default position' for those with questionable capacity. ${ }^{6}$ The older patients concerned would often fade into the background during these decision-making processes, so their long-standing preferences were not heard. ${ }^{7}$

GPs with an appropriate understanding of the principles and ethos of the MCA lincluding the Deprivation of Liberty Safeguards) can be very influential in their 'patient advocate' role, when the rights of people whose home which is so much a part of who we all are - is under scrutiny in relation to their health, care, and wellbeing

Charlotte Ann Emmett,

Senior Law Lecturer, Northumbria University, School of Law, Newcastle upon Tyne.

E-mail: charlotte.emmettanorthumbria.ac.uk

John Gration,

GP/occupational physician.

\section{REFERENCES}

1. Bally K, Jung C. Caring for older people: is home care always best? Br J Gen Pract 2015; DOI: 10.3399/ bjgp15X687265.

2. Bradshaw SA, Playford ED, Riazi A. Living well in care homes: a systematic review of qualitative studies. Age Ageing 2012; 41(4): 429-440.

3. Eisele M, Kaduszkiewicz $\mathrm{H}$, König $\mathrm{H}-\mathrm{H}$, et al. Determinants of health-related quality of life in older primary care patients: results of the longitudinal observational AgeCoDe study. Br J Gen Pract 2015; DOI: 10.3399/bjgp15X687337.

4. Nikmat AW, Al-Mashoor SH, Hashim NA. Quality of life in people with cognitive impairment: nursing homes versus home care. Int Psychogeriatr 2015; 27(5): 815-824

5. Select Committee on the Mental Capacity Act 2005 Mental Capacity Act 2005: post-legislative scrutiny. 2014. http://uww.publications.parliament.uk/pa/ ld201314/ldselect/ldmentalcap/139/13902.htm (accessed 27 Nov 2015).

6. Emmett C, Poole M, Bond J, Hughes J. Homeward bound or bound for a home? Assessing the capacity of dementia patients to make decisions about hospital discharge: comparing practice with legal standards. Int J Law Psychiatry 2012; 36(1): 73-82.

7. Emmett C, Poole M, Bond J, Hughes JC. A relative safeguard? The informal roles that families and carers play when patients with dementia are discharged from hospital into care in England and Wales. Int J Law Policy Family2014: 28(3): 302-320.

DOI: 10.3399/bjgp16X683113

\section{Can we trust studies using audit software?}

We must say how disappointed we were on reading the paper 'Can we trust studies using audit software?' by Rice et al.' We certainly hope it does not have an adverse effect on the use of the GRASP tools in the future, as our experience with them has been very positive.

First, one must question how representative this experience of one practice is.

Second, much of the difference between the GRASP-AF results and the 'manual' search used in the paper lwhich actually was an electronic audit too as they used the practice computer system to do this) is clearly due to a difference in the definition of AF used in the two methods and in the high use of free text in this practice to record exclusions.

The manual search described looked for patients with 'unresolved' AF, which allows GPs to exclude some high-risk patients from the audit, whereas GRASP-AF searches for a 'history of AF'. Therefore, the GRASP search includes patients that the QOF would exclude under the category of 'resolved'. As we know, no audit software can search free-text entries, hence the need to ensure accurate coding is used in the first place. The use of free text rather than predefined Read codes to record patient refusal or contraindication explains why the software could not identify patients. This highlights issues about appropriate use of coding in this practice rather than any inherent problem with the audit software.

One important feature of the GRASP-AF audit software was omitted from this paper: that GRASP offers the opportunity to easily share anonymised data for benchmarking using CHART Online. We feel the article missed an important opportunity to show that the issue is not about comparing automated versus manual processes, but rather how best to make use of our most precious resource clinical time. The paper's proposal to return to manual audit will exasperate already busy GPs. Clearly the only sensible option for the future is to use audit software and ensure that coding is improved so that the results are as accurate as possible.

Craig Wakeham,

GP, Cerne Abbas Surgery, Cerne Abbas, Dorchester, Dorset

E-mail: craig.wakehamagp-j81053.nhs.uk

Richard Healicon,

Programme Delivery Lead, Sustainable Improvement Team, NHS England.

Miriam Lemar

Commercial Director, PRIMIS

\section{REFERENCE}

1. Rice R, Roberts L, Fitzmaurice D. Can we trust studies using audit software? A case study of atrial fibrillation audit. Br J Gen Pract 2015; DOI: 10.3399/ bjgp15X687457.

\section{DOI: 10.3399/bjgp16X683125}

\section{Correction}

In the December article by Pedersen AF, et al. Association of GPs' risk attitudes, level of empathy, and burnout status with PSA testing in primary care. $\mathrm{Br}$ Gen Pract 2015; DOI: 10.3399/bjgp15X687649, Figure 1 incorrectly stated 'prostrate' instead of 'prostate'. We apologise for this error and the online version has been corrected. DOI: 10.3399/bjgp16X683137 